\title{
XVII. THE HYDROLYSIS OF GLYCOGEN BY A GLYCEROL EXTRACT OF MUSCLE
}

\author{
By ANITA MARY WALKER ${ }^{1}$ AND FRANK GEORGE YOUNG \\ From the Department of Biochemistry, University College, London
}

(Received 24 November 1937)

BARBOUR [1929] found that when glycogen is hydrolysed by a glycerol extract of skeletal muscle or of liver, the reducing activity appearing, expressed as glucose, is only about $30 \%$ of the glycogen disappearing. Case [1931] and Gray [1935] were able to confirm this observation, but Carruthers [1935] did not obtain consistent results. From the products of hydrolysis Barbour isolated, by a relatively simple method, a substance which he identified as a trisaccharide. Carruthers \& Lee [1935] and Gray were, however, unable to repeat this isolation, and Carruthers [1935] brought forward evidence which he believed to indicate that a mixture of maltose and dextrin, and not a trisaccharide, results from the hydrolysis of glycogen by a glycerol extract of muscle or liver tissues. Winter [1937] finds that the end product of the action of a glycerol extract of heart muscle on glycogen is glucose, although he believes that a trisaccharide, rather than a disaccharide, may be formed intermediately.

The present investigation was undertaken to confirm, if possible, the statement that a trisaccharide is formed by the hydrolysis of glycogen under the conditions described by Barbour, and to examine the chemical nature of the purified material.

\section{Methods}

Glycogen was prepared from rabbit liver and from Mytilus edulis by Pflüger's method. All the specimens used had $[\alpha]_{D}$ close to $+195^{\circ}$ and ash content about $0.25 \%$. Glycogen was estimated by the method of Evans et al. [1931], sugar being determined by the method (Reagent 50) of Shaffer \& Somogyi [1933].

A glycerol extract of rabbit muscle was prepared by the method of Hunter \& Dauphinee [1924].

\section{Results}

\section{Hydrolysis of glycogen by a glycerol extract of muscle}

In Table I are given typical results for the hydrolysis of $100 \mathrm{ml}$. of a $3.5 \%$ solution of glycogen in phosphate buffer at $p \mathrm{H} 6.4$ by $25 \mathrm{ml}$. of a glycerol extract of rabbit skeletal muscle. The hydrolysis was carried out in the presence of toluene at $37^{\circ}$. The ratio (reducing power appearing)/(glycogen disappearing) is somewhat greater than the value $(1 / 3)$ which might be expected if a trisaccharide were formed, although the difference is not large. The final reducing power in a large number of hydrolyses has been very close to $38 \%$ of the amount of glycogen disappearing. These results might be considered to indicate that a trisaccharide is formed by the hydrolysis of glycogen by a glycerol extract of muscle. Nevertheless, it seemed possible that the primary product of the hydrolysis might be glucose or maltose, and that a trisaccharide had been formed

1 Work carried out during the tenure of a Carnegie Research Scholarship. 
Table I

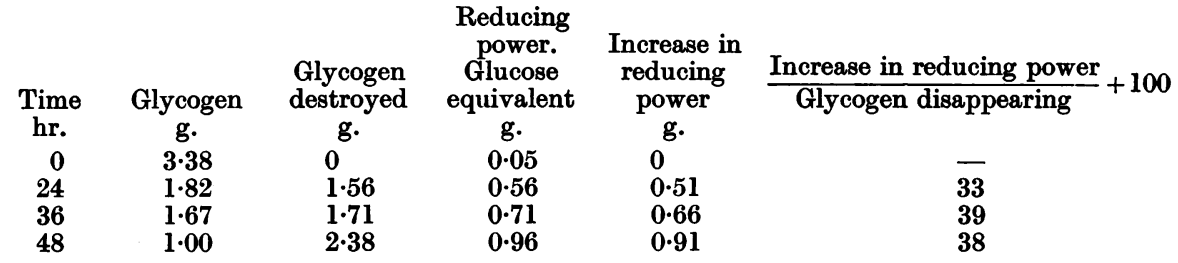

secondarily under the influence of the glycerol or of the enzyme. Accordingly the control experiments shown in Table II were carried out. In each case a suitable concentration of the sugar in phosphate buffer at $p \mathrm{H} 6.4$ was mixed with $25 \%$ of its volume of glycerol or glycerol extract of rabbit muscle, and

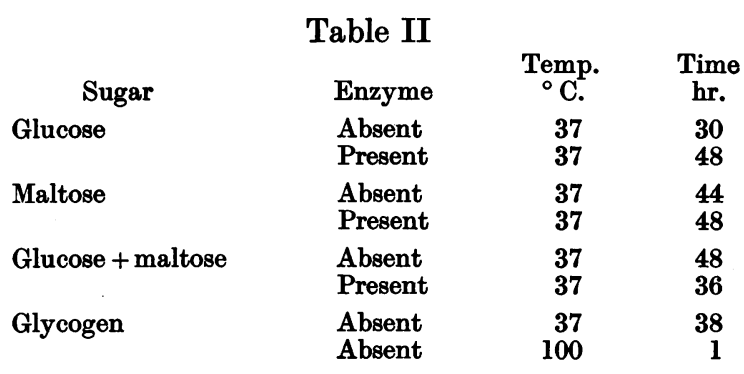

incubated at $37^{\circ}$ in the presence of toluene, or heated to $100^{\circ}$. In no case was any significant change of rotatory power or reducing activity found in these control experiments, and it seemed probable that the figures indicating the possible production of a trisaccharide by the hydrolysis of glycogen, were of primary importance.

\section{Attempts to isolate the products of hydrolysis}

Barbour states "the sugar itself was... isolated by precipitation as a barium compound on the addition of excess barium hydroxide from a solution in $70 \%$ alcohol. This compound was dissolved in water, decomposed by a current of $\mathrm{CO}_{2}$, the last trace of barium removed with sulphuric acid, and the filtrate evaporated to dryness. The sugar was purified by a repetition of this procedure". We have repeatedly attempted to obtain a purified sugar by this simple process but in every case the product has contained a very high proportion of ash. The addition of barium hydroxide to an aqueous solution of the products of hydrolysis results in a precipitate which appears to consist almost entirely of barium phosphate. Accordingly this precipitate has been discarded in many cases, the carbohydrate material being subsequently precipitated from solution in the presence of excess barium hydroxide by the addition of alcohol to make $70 \%$. Repetition of this process, followed by evaporation at low température, yielded a syrup which could be dried to an amorphous white powder containing about $10 \%$ of ash and having a reducing power about $14 \%$ that of glucose. The yield was approximately $5 \%$ of the glycogen hydrolysed. When pure maltose, dissolved in phosphate buffer, was subjected to the above process of isolation it acquired about $15 \%$ of ash, and it seemed unlikely that this process could be expected to yield an ash-free material from the products 
of hydrolysis of glycogen. Numerous unsuccessful attempts to diminish the ash content of the products of glycogen hydrolysis were made by fractional precipitation with methyl and ethyl alcohols at different $p \mathrm{H}$, and with alcoholether mixtures. Finally a modification of the copper-baryta precipitation method of Fleury \& Ambert [1929] was applied. This process, which gave a $70 \%$ recovery of carbohydrate material, yielded a product having an ash content of $4.8 \%$; repetition of the process failed to reduce the ash content further. Acetylation of the product with acetic anhydride in pyridine, followed by purification of the acetylated material, gave an acetyl derivative with an ash content of $1 \cdot 6 \%$. The original product and the acetyl derivative were both analysed, the results being calculated on an ash-free basis.

\section{Properties of the unacetylated product}

The product was an amorphous white, slightly hygroscopic powder, easily soluble in water but insoluble in organic solvents. Its reducing power was $14 \%$ of that of glucose, and its $[\alpha]_{D}$ was $+171^{\circ}$. It yielded a phenylosazone of a form similar to that described by Barbour-small star-shaped aggregates of needlesbut attempts to recrystallize this derivative were not successful. The original product was rapidly hydrolysed on heating with $2.4 \% \mathrm{HCl}$ at $100^{\circ}$. Glucose appeared to be the main hydrolytic product and was identified by the crystalline form of the osazone and its melting point when mixed with an authentic specimen of glucosazone. The course of acid hydrolysis was followed polarimetrically and by reducing activity, the results being plotted in Fig. 1. The hydrolysis is practically complete in $90 \mathrm{~min}$. under these conditions.

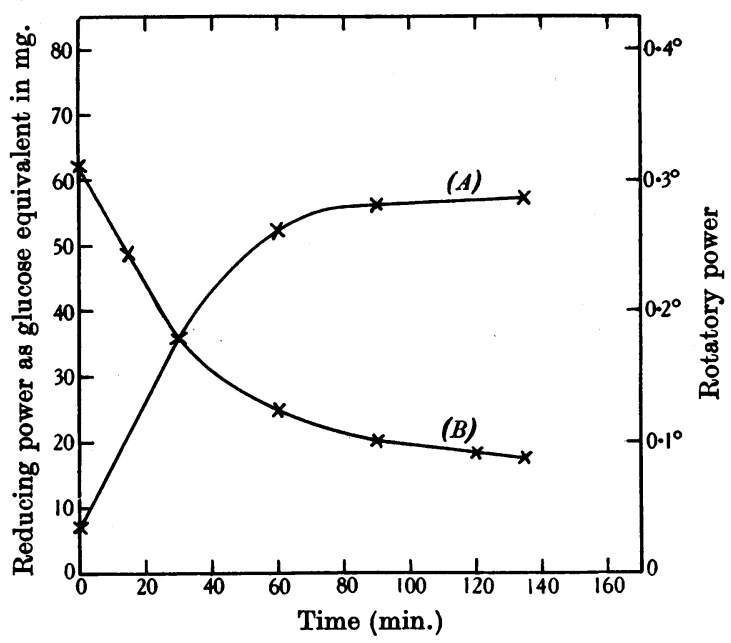

Fig. 1. Hydrolysis curve for $50.8 \mathrm{mg}$. of product dissolved in $26.5 \mathrm{ml}$. of $2.4 \% \mathrm{HCl}$ and heated at $100^{\circ}$. Course of hydrolysis followed by reducing power (curve $A$ ) and by rotatory power (curve $B$ ).

Elementary analysis of the original product gave $\mathrm{C}=41.50 \%, \mathrm{H}=6.81 \%$ (calculated for a trisaccharide- $\mathrm{C}=42.86 \%, \mathrm{H}=6.35 \%$ ). Ash $=4.8 \%$, containing only a trace of phosphorus. 


\section{Properties of the acetyl derivative}

The product of acetylation was an amorphous white powder, insoluble in water, but soluble in the usual organic solvents. In chloroform solution $[\alpha]_{D}=+92^{\circ}$. Elementary analysis gave $\mathrm{C}=\mathbf{4 9 \cdot 2 3} \%, \mathrm{H}=\mathbf{5 \cdot 7 5} \%$ (calculated for a trisaccharide having 11 hydroxyl groups acetylated-C=49.70\%, $\mathrm{H}=5 \cdot 63 \%$ ). Ash content $=1.6 \%$. Acetyl content $=48.6 \%$ (calculated for a trisaccharide having 11 hydroxyl groups acetylated $-48.97 \%$ ); mol. wt. (Rast) $=1010$ (calculated for a fully acetylated trisaccharide-966).

\section{Discussion}

Barbour [1929] considers that the glycerol extract of muscle he used contains a glycogenase whose action on glycogen yields a trisaccharide as the sole product of hydrolysis. Carruthers [1935] brought forward evidence to show that a glycerol extract of muscle contains both diastase and maltase, although the action of the maltase is partly inhibited in the presence of glycerol. This author inclines to the view that such an extract hydrolyses glycogen to a mixture of maltose and non-reducing dextrin, although the possibility that a small amount of trisaccharide is formed could not be completely ruled out. Although we have obtained more consistent results with the hydrolysis of glycogen than did Carruthers [1935] [cf. Case, 1931; and Gray, 1935], nevertheless the reducing power appearing has always been more than $30 \%$ of the glycogen disappearing, the average figure being about $38 \%$. Carruthers's belief that his results more probably indicate the formation of a mixture of maltose and dextrin than that of a trisaccharide is based more on an investigation of the nature of the enzyme system concerned than on examination and purification of the product prepared according to Barbour's directions. The majority of the experiments of Carruthers, and of Carruthers \& Lee, were carried out with a dialysed, glycerol-free enzyme preparation. As these authors indicate, such experiments cannot decide whether or not a trisaccharide can be isolated under the conditions of Barbour's experiments. Evidence bearing on this question must come from an attempted repetition of Barbour's investigations.

Barbour does not say whether or not his preparations contained ash, but it seems, from our results, that he could hardly have obtained an ash-free product by the simple method of barium precipitation he describes for the isolation of the free sugar. Carruthers \& Lee found that "attempts to purify fractions by precipitation with barium hydroxide were unsuccessful". The high ash content has been a most troublesome feature of our preparations, and although our analytical figures have been corrected for ash, the high ash content of the preparation necessarily introduces an uncertainty into the interpretation of any analytical results.

As well as isolating a trisaccharide Barbour obtained a compound of lower reducing power which he believed to be an anhydrotrisaccharide, formed from the trisaccharide by the removal of one molecule of water. This compound had a reducing power only $8.5 \%$ of that of glucose, compared with $31 \%$ for the trisaccharide, but otherwise its properties were not very different from those of the latter compound. The product obtained in the present investigation appears to resemble Barbour's anhydrotrisaccharide rather than his trisaccharide, as judged by the comparatively low reducing power of our preparation $(14 \%)$.

Pringsheim [1924] isolated a substance which he called "amylotriose" by the hydrolysis of glycogen or amylopectin with cold concentrated HCl. Lohmann

Biochem. 1938 xxxII 
[1926], investigating the diastatic hydrolysis of glycogen, isolated a sugar which he suggested might be identical with Pringsheim's amylotriose. Barbour believes, on the basis of difference in rotation and reduction, that his trisaccharide is different from that of Pringsheim or of Lohmann. The properties of the various presumed trisaccharides formed from glycogen are summarized in Table III, the properties of the corresponding acetyl derivatives being given in

\section{Table III}

\begin{tabular}{|c|c|c|c|c|c|}
\hline Author & {$[\alpha]_{D}$} & $\begin{array}{c}\text { Reducing } \\
\text { power } \\
\text { (glucose }= \\
100 \text { ) }\end{array}$ & $\begin{array}{c}\text { Mol. wt. } \\
\text { (theory }= \\
504)\end{array}$ & $\begin{array}{c}\% \\
\text { carbon } \\
\text { (theory }= \\
\mathbf{4 2 \cdot 8 6})\end{array}$ & $\begin{array}{c}\% \\
\text { hydrogen } \\
\text { (theory }= \\
6 \cdot 35)\end{array}$ \\
\hline $\begin{array}{l}\text { Pringsheim } \\
\text { Lohmann } \\
\text { Barbour } \\
\text { Present authors }\end{array}$ & $\begin{array}{c}+124^{\circ} \\
137 \cdot 5 \\
154 \\
171\end{array}$ & $\begin{array}{c}26 \\
9 \cdot 7 \\
31 \\
14\end{array}$ & $\begin{array}{c}513 \\
480 \\
505 \\
-\end{array}$ & $\begin{array}{l}42 \cdot 72 \\
-\overline{42 \cdot 85} \\
41 \cdot 50\end{array}$ & $\begin{array}{l}6 \cdot 47 \\
6 \cdot 34 \\
6 \cdot 81\end{array}$ \\
\hline $\begin{array}{l}\text { Barbour (anhydro- } \\
\text { trisaccharide) }\end{array}$ & $158^{*}$ & 8.5 & $\begin{array}{c}481 \dagger \\
\text { (theory }=486)\end{array}$ & - & - \\
\hline
\end{tabular}

* Calculated from the $[\alpha]_{\mathrm{Hg}}$ of $187^{\circ}$ given by Barbour. As Carruthers \& Lee point out, the data given by Barbour establishes the $[\alpha]_{H_{1}}$ as $374^{\circ}$, and not $187^{\circ}$, the figure Barbour gives.

$\dagger$ As Carruthers \& Lee point out, the data given by Barbour establishes the mol. wt. as 240 and not 481 .

\begin{tabular}{|c|c|c|c|c|c|}
\hline Author & {$[\alpha]_{D}^{\mathrm{CHCl}_{\mathbf{3}}}$} & $\begin{array}{c}\text { Mol. wt. } \\
\text { (theory }= \\
966)\end{array}$ & $\begin{array}{c}\text { Acetyl } \\
\text { content } \\
\text { (theory= } \\
\mathbf{4 8 . 9 7 \% )}\end{array}$ & $\begin{array}{c}\% \\
\text { carbon } \\
\text { (theory= } \\
49 \cdot 67)\end{array}$ & $\begin{array}{c}\% \\
\text { hydrogen } \\
\text { (theory = } \\
\mathbf{5 \cdot 6 3 )}\end{array}$ \\
\hline $\begin{array}{l}\text { Pringsheim } \\
\text { Lohmann } \\
\text { Present authors }\end{array}$ & $\begin{array}{c}+125^{\circ} \\
127 \\
92\end{array}$ & $\begin{array}{l}1020 \\
1010 \\
1010\end{array}$ & $\begin{array}{l}47 \cdot 41 \\
46 \cdot 20 \\
48 \cdot 60\end{array}$ & $\begin{array}{l}-\overline{48 \cdot 78} \\
49 \cdot 23\end{array}$ & $\begin{array}{l}\overline{-} \\
5 \cdot 72 \\
5 \cdot 75\end{array}$ \\
\hline $\begin{array}{l}\text { Barbour (anhydro- } \\
\text { trisaccharide) }\end{array}$ & - & $\begin{array}{c}961 \\
\text { (theory }= \\
906)\end{array}$ & $\begin{array}{c}47 \cdot 5 \\
(\text { theory }= \\
47 \cdot 5)\end{array}$ & - & - \\
\hline
\end{tabular}

Table IV. It seems unlikely from the figures collected here that any one of these products can be identical with any other, and adequate evidence that any of them is a single substance is lacking. The results obtained by the present authors for the acetyl derivative are reasonably close to the theoretical figures for an undeca-acetyl trisaccharide, but it would be unwise to suggest, on this basis alone, that the isolated material consists of a trisaccharide. The data believed by the various authors to characterize a trisaccharide might easily be obtained from a mixture of glucose, maltose and reducing dextrin or oligosaccharide [cf. Carruthers, 1935]. The preparation of an osazone having a characteristic crystalline appearance and a nitrogen content similar to that required for the osazone of a trisaccharide has often been cited as evidence for the existence of a trisaccharide. The doubtful value of such evidence is clear from a recent review by Ling [1937] of the nature of certain hydrolytic products from starch. Ling concludes that many of the supposed substances intermediate between starch and maltose, including a presumed trisaccharide, are co-ordination compounds of maltose and non-reducing dextrin. Particularly instructive is the case of the so-called "isomaltose" for which a characteristic osazone has frequently been described. Ling points out that it is practically impossible to separate "isomaltose" into its constituents by fractionation with alcohol; nevertheless it appears to be a mixture of substances, and the appearance of "isomaltosazone" can be simulated by recrystallizing maltosazone in the presence of dextrin. It 
is clear that the nitrogen content of an "osazone" of this type might easily approach that for the osazone of a trisaccharide.

Until a purified trisaccharide with well-characterized crystalline derivatives can be obtained in amount sufficient to permit an extensive examination, the question of whether or not a trisaccharide can be formed by the hydrolysis of glycogen should remain open. The evidence available certainly does not warrant the assumption that a definitive trisaccharide ever constitutes the major portion of the products of glycogen hydrolysis.

\section{EXPERIMENTAL}

Purification of crude product from glycogen hydrolysis [cf. Fleury \& Ambert, 1929]. $1 \mathrm{~g}$. of the product obtained according to Barbour's directions was dissolved in $10 \mathrm{ml}$. of water and treated with small amounts of $20 \% \mathrm{CuSO}_{4}$ and $N / 3 \cdot 6 \mathrm{Ba}(\mathrm{OH})_{2}$ solutions alternately until total volumes of 21.5 and $240 \mathrm{ml}$. respectively had been added. The mixture was stirred at $0^{\circ}$ for $1 \mathrm{hr}$. and the precipitate centrifuged off and suspended in water. $50 \% \mathrm{H}_{2} \mathrm{SO}_{4}$ was added until just acid to Congo red, and the precipitated $\mathrm{BaSO}_{4}$ centrifuged off and discarded. The copper in the filtrate was removed by $\mathrm{H}_{2} \mathrm{~S}$ and, after aeration, the solution was freed from $\mathrm{Ba}^{++}$ions and $\mathrm{SO}_{4}^{--}$ions by the addition of appropriate amounts of $\mathrm{Ba}(\mathrm{OH})_{2}$ and $\mathrm{H}_{2} \mathrm{SO}_{4}$. The solution was concentrated to a syrup under reduced pressure and dried with alcohol to an amorphous powder. Yield =0.7 g. i.e. $70 \%$.

Analysis of the product.

$4 \cdot 195 \mathrm{mg}$. gave $6.080 \mathrm{mg}$. $\mathrm{CO}_{2}$ and $2.450 \mathrm{mg}$. $\mathrm{H}_{2} \mathrm{O}$. Res. $=0.202 \mathrm{mg}$. (Weiler), whence $\mathrm{C}=41.50 \%$ and $\mathrm{H}=6 \cdot 81 \%$. Ash $=4 \cdot 8 \%$.

$22.84 \mathrm{mg}$. in $25 \mathrm{ml} . \mathrm{H}_{2} \mathrm{O}$ gave $\alpha=+0 \cdot 148^{\circ} ; l=1$, whence $[\alpha]_{D}=+170 \cdot 6^{\circ}$.

$22.84 \mathrm{mg}$. in $25 \mathrm{ml}$. $\mathrm{H}_{2} \mathrm{O}$ estimated as $3.03 \mathrm{mg}$. glucose by Shaffer-Somogyi method. Reducing power is therefore $13.9 \%$ that of glucose.

Hydrolysis curves. $50.80 \mathrm{mg}$. of product were dissolved in $25 \mathrm{ml}$. of $\mathrm{H}_{2} \mathrm{O}$ and $1.5 \mathrm{ml}$. of concentrated $\mathrm{HCl}$ added. The course of hydrolysis on heating to $100^{\circ}$ was followed polarimetrically [cf. Young, 1937] and by the estimation of reducing power.

$\begin{array}{ccc}\begin{array}{c}\text { Time } \\ \text { min. }\end{array} & \begin{array}{c}\text { Rotation } \\ \bullet\end{array} & \begin{array}{c}\text { Reducing power } \\ \text { mg. equiv. glucose }\end{array} \\ 0 & +0 \cdot 312\left([\alpha]_{D}^{\mathrm{HCl}}=+171^{\circ}\right) & \mathbf{7 \cdot 2} \\ 15 & 0 \cdot 243 & - \\ 30 & 0 \cdot 177 & \mathbf{3 5 \cdot 8} \\ 60 & 0 \cdot 124 & 52 \cdot 4 \\ 90 & 0 \cdot 102 & 56 \cdot 0 \\ 120 & 0 \cdot 093 & - \\ 135 & 0 \cdot 085 & 56 \cdot 9 \\ \text { Theoretical } & 0 \cdot 102 & 51 \cdot 8\end{array}$

Acetylation. $150 \mathrm{mg}$. of product were heated with $0.9 \mathrm{ml}$. of pyridine and $0.6 \mathrm{ml}$. of acetic anhydride to $50^{\circ}$ for $2 \mathrm{hr}$., and left overnight at room temperature. The mixture was filtered into ice-cold water and the precipitate spun off, dissolved in dry chloroform and evaporated to dryness after moisture had been removed by standing over anhydrous $\mathrm{Na}_{2} \mathrm{SO}_{4}$. The residue was dissolved in hot, absolute alcohol. On cooling, the solution deposited an amorphous white powder which was centrifuged and dried in vacuo. Yield $=23 \mathrm{mg}$., i.e. $12 \%$ of theoretical.

Analysis of acetyl derivative.

$3.560 \mathrm{mg}$. gave $6.320 \mathrm{mg}$. $\mathrm{CO}_{2}$ and $1.810 \mathrm{mg}$. $\mathrm{H}_{2} \mathrm{O}$. Res. $=0.06 \mathrm{mg}$. (Weiler), whence $\mathrm{C}=49 \cdot 23 \%$ and $\mathrm{H}=5 \cdot 75 \%$. Ash $=1 \cdot 6 \%$.

$0.646 \mathrm{mg}$. in $6.028 \mathrm{mg}$. camphor depressed melting-point by $4 \cdot 2^{\circ}$ (Weiler); mol. wt. $=1010$.

$10.303 \mathrm{mg}$. liberated equiv. $11.45 \mathrm{ml}$. $N / 100 \mathrm{NaOH}$ on complete hydrolysis. Acetyl content $=48 \cdot 6 \% O . \mathrm{CH}_{3}$.

$14.58 \mathrm{mg}$. in $10 \mathrm{ml} . \mathrm{CHCl}_{3}$ gave $\alpha=+0.067^{\circ} ; l=0.5$ whence $[\alpha]_{D} \mathrm{CHCl}_{3}=+91.9^{\circ}$. 


\section{SUMMARY}

1. Barbour's statement that when glycogen is hydrolysed by a glycerol extract of rabbit muscle the reducing power appearing, calculated as glucose, is only about one-third of the amount of glycogen disappearing, has not been entirely confirmed, in that the reducing power appearing in our experiments was about $38 \%$ of the glycogen disappearing.

2. Attempts to prepare a purified trisaccharide according to Barbour's directions invariably yielded a product containing a large amount of ash. However, an acetyl derivative was prepared whose analytical results were close to those for an undeca-acetyl trisaccharide. The possibility that the analytical figures obtained might be given by a mixture of maltose and oligosaccharide or dextrin is stressed. The relationship of the results of the present investigation to those of Pringsheim, Lohmann and Barbour is discussed.

3. The conclusion is drawn that until a purified trisaccharide with wellcharacterized crystalline derivatives can be prepared from glycogen in amount sufficient to permit extensive examination, the question of whether or not a trisaccharide can be formed by the hydrolysis of glycogen should remain open.

We wish to express our thanks to Prof. J. C. Drummond for his advice and criticism.

\section{REFERENCES}

Barbour (1929). J. biol. Chem. 85, 29.

Carruthers (1935). J. biol. Chem. 108, 535.

— \& Lee (1935). J. biol. Chem. 108, 525.

Case (1931). Biochem. J. 25, 561.

Evans, Tsai \& Young (1931). J. Physiol. 73, 67.

Fleury \& Ambert (1929). C.R. Acad. Sci., Paris, 189, 1282.

Gray (1935). Nature, Lond., 135, 1002.

Hunter \& Dauphinee (1924). Proc. roy. Soc. B, 97, 209.

Ling (1937). Chem. Ind. Rev. 56, 346.

Lohmann (1926). Biochem. Z. 178, 444.

Pringsheim (1924). Ber. dtsch. chem. Ges. 57, 1581.

Shaffer \& Somogyi (1933). J. biol. Chem. 100, 695.

Winter (1937). Biochem. J. 31, 236.

Young (1937). Biochem. J. 31, 711. 